\title{
Aprendizagem no Processo de Seleção de Ferramenta CASE para o Estado da Bahia
}

\author{
Elizabeth Loiola \\ Maria Célia Furtado Rocha
}

\section{Resumo}

Este artigo objetiva discutir os fatores que condicionaram os processos de aprendizagem dos membros da Comissão de Seleção de Ferramenta CASE para o Estado da Bahia. Evidenciar tais fatores é importante porque, embora sejam fenômenos diferentes, a aprendizagem organizacional depende da aprendizagem individual. Os resultados das entrevistas com membros da Comissão de Seleção de Ferramenta CASE para o Estado da Bahia, realizadas com base em roteiro com setenta e duas questões abertas e após três meses de concluído o processo, parecem confirmar muitos dos postulados da abordagem anteriormente referida, principalmente aqueles que indicam que o processo de aprendizagem dos indivíduos nas organizações é condicionado por fatores do próprio indivíduo, do grupo e dos contextos, refletindo a percepção de que a cognição é um processo intra e interpsíquico.

Palavras-chaves: aprendizagem organizacional; aprendizagem individual; abordagem cognitivoconstrutivista.

\section{Abstract}

This paper is intended to analyse the determinant factors of organizational learning based upon a cognitive-constructivist focus. The case-study was conducted in the state of Bahia, Brazil, in a public committee for software selection. Their members was enterviewed and talked about what determined learning. The factors which came out from the research were related with context, group and person. The results, although preliminary, confirm many of the postulations of cognitiveconstructivist approach.

Key words: organizational learning; individual learning; cognitive-construtivist approach. 


\section{INTRODUÇÃO}

O tema aprendizagem organizacional ganha maior importância com a aceleração do surgimento e da renovação dos saberes e savoir-faire na sociedade do conhecimento. Nessa sociedade emerge uma nova natureza do trabalho, cuja parte relacionada à transação de conhecimentos não pára de crescer, na opinião de Lévy (1993). O autor chama a atenção para as novas tecnologias intelectuais que circulam no ciberespaço, amplificando, exteriorizando e modificando várias funções cognitivas humanas.

Apesar das expressivas transformações na natureza do saber, do trabalho e das tecnologias de inteligência, acredita-se continuar válido o postulado de ser a aprendizagem do indivíduo fruto da interação de fatores intra-psíquicos com fatores interpsíquicos. Tal postulado põe em relevo a importância, para o processo de aprendizagem, da relação indivíduo-contexto, em perspectiva que permite enquadrar e tornar intelegíveis as mudanças das problemáticas da educação e da formação nas sociedades do conhecimento, referidas por Lévy (1993). Talvez por isso tem sido crescentemente explorado pela literatura de aprendizagem organizacional, na vertente denominada neste artigo cognitivo-construtivista. Um dos desafios a serem vencidos pelos estudiosos dessa linhagem é o desenvolvimento de uma metodologia de pesquisa, que permita apreender a multideterminação e dinâmica da aprendizagem organizacional, sem reduzi-la ao fenômeno de aprendizagem individual.

Este artigo relata os resultados de uma pesquisa que não tem a pretensão de abraçar esse desafio. Seu objetivo é muito menos ambicioso: é discutir fatores que condicionam processos de aprendizagem de indivíduos nas organizações. Evidenciar tais fatores é importante porque, embora sejam fenômenos diferentes, a aprendizagem organizacional depende da aprendizagem individual. Ao aumentar o conhecimento sobre esses fatores, espera-se, adicionalmente, contribuir para o progresso da compreensão do processo de aprendizagem organizacional e para a formulação de modelos e metodologias consistentes com o enfoque cognitivo-construtivista.

Para alcançar o objetivo citado, foi realizada uma pesquisa qualitativa junto aos membros da Comissão de Seleção de Ferramenta CASE, três meses após eles vivenciarem uma experiência pioneira. Essa comissão foi instituída pela Companhia de Processamento de Dados do Estado da Bahia (PRODEB) para desenvolver uma metodologia de avaliação e escolher uma ferramenta capaz de 
automatizar os processos de engenharia de software, cujo uso seria difundido entre os órgãos do governo.

A estrutura deste artigo é a que se segue. No próximo item, apresenta-se breve revisão das principais discussões sobre aprendizagem organizacional. Dada a relevância das contribuições de Hebert Simon para o campo do conhecimento sobre aprendizagem, logo após procura-se resgatar as principais proposições desenvolvidas em sua obra clássica, Comportamento Administrativo. A seguir registram-se os procedimentos metodológicos e os antecedentes que envolvem a descrição de toda a fase de preparação do trabalho da comissão, o detalhamento da metodologia adotada para a seleção e os resultados alcançados. Os resultados das avaliações de cada membro sobre o seu aprendizado são relatados na seqüência. O item posterior descreve os fatores condicionantes do processo de aprendizagem do grupo, a partir da visão de seus membros. Por fim, são apresentadas as conclusões do esforço de pesquisa e suas limitações.

\section{Aprendizagem Organizacional: Breve Visão do Campo}

A partir de meados da década de 70 do século anterior, os modelos clássicos de organização começaram a se mostrar pouco exitosos em função do acirramento da competição nos mercados, o que trouxe novas imposições no que se refere ao aumento da qualidade dos produtos e serviços ofertados e da eficiência nos processos produtivos. É quando cresce a preocupação com o processo de aprendizagem organizacional e as estruturas que lhe dão apoio. Talvez por esse motivo, os estudos geralmente tendem a associar aprendizagem a mudança organizacional e tratam de idealizar esquemas a partir dos quais direcioná-la (Cook e Yanow, 1996; Huysman, 19_ _ ).

Bastos (2000a, 2000b), refletindo sobre a conexão do cognitivismo com a aprendizagem organizacional, identificou que, há muito, a organização já é objeto de olhares cognitivistas, voltando-se os primeiros ensaios para a análise dos processos micro-organizacionais indivíduo/organização. Todavia a crescente importância dada à visão do fenômeno organizacional enquanto socialmente construído pela interação entre atores relevantes, associa-se à recuperação do significado mais antigo de organizações como processo e à perda de importância do construto de organização como entidade (Bastos, 2000a). Em conseqüência, o foco da atenção dos estudiosos tendeu a deslocar-se para o nível grupal, redes sociais, cognição gerencial, construção de sentidos, o papel das metas e do autogerenciamento e a cognição individual e organizacional. 
Entre as disciplinas do campo da administração que têm aberto maior espaço para as questões envolvidas com a aprendizagem organizacional, Brito e Brito (1997) destacam Gestão Estratégica e Inovação. Em relação a essas disciplinas, os trabalhos de Simon (1970), Mintzberg e Waters (1985), Nelson (1987), Dosi, Teece e Winter (1992), Levitt e March (1996), Weick (1996), Winter (1996), entre outros, são referências que não se podem desconhecer.

Focalizando o campo dos estudos sobre inovações, alguns de seus autores têm enfatizado os processos por meio dos quais as organizações aprendem. Falam em learning by doing, learning by using e learning by interacting, para dar conta tanto de processos que se realizam no âmbito interno das organizações como daqueles que transcendem os seus limites, para sublinhar que as organizações aprendem consigo mesmas e com as outras.

Ajustando o foco sobre os trabalhos de Simon (1970), Levitt e March (1996) e Weick (1996), referidos anteriormente, ressalta a preocupação em investigar as formas pelas quais as organizações desenvolvem frameworks ou paradigmas, a partir dos quais as suas próprias experiências são interpretadas, o que põe em evidência a problemática das representações, ou seja, a possibilidade de desacordos em torno do significado da experiência, da história.

Hebert Simon, já em 1945, em seu livro Comportamento Administrativo, atribuía à organização o importantíssimo papel de estabelecer as condições para a aprendizagem, proporcionando o ambiente capaz de ampliar a racionalidade do indivíduo. Segundo esse autor, ao direcionar a atenção e ao permitir que cada indivíduo do grupo forme sólidas expectativas quanto ao comportamento dos demais membros, a organização acaba por estabelecer as condições para a ação e para a consideração racional das conseqüências da ação num grupo social. Deste modo "a racionalidade humana recebe [...] seus objetivos e integrações do ambiente institucional em que opera e pelo qual é moldada” (Simon, 1970, p. 106).

A seguir, discutem-se as principais contribuições desse autor para a teoria da aprendizagem organizacional, no que se refere à constituição de frameworks que orientam a ação dos membros das organizações, de acordo com a interpretação de suas experiências. 
Hebert Simon: Organizações como Processos de Tomada de Decisão ou o Processo de Construção de Framework nas Organizações

Encarando as organizações priomordialmente como processos de tomada de decisão, que envolvem a cooperação coordenada de seus participantes em busca da realização dos objetivos organizacionais, Simon (1970, p. 73) está atento à complexidade do comportamento grupal, uma vez que "cada indivíduo deve saber quais são as reações dos demais, a fim de determinar de maneira adequada as consequiências de suas próprias ações”. Organizações seriam, então, sistemas de comportamento cooperativo orientados pelo planejamento, o qual tem por função não apenas alocar os participantes, mas, sobretudo, "permitir que cada um tenha certeza em relação ao que os outros irão fazer" (Simon, 1970, p. 74). Assim, o autor elabora um modelo de organização racional sustentado na comunicação dos comportamentos a seus participantes, uma vez que a correta seleção de estratégias fundamenta-se no "conhecimento de cada uma das estratégias selecionadas pelos outros” (Simon, 1970, p. 76).

\section{A Tomada de Decisões nas Organizações}

A ação racional, definida como aquela orientada a determinada finalidade, resulta do processo de escolha de uma entre muitas alternativas possíveis, esteja ou não presente o elemento consciente, deliberado. Envolve seleção de metas e comportamentos relacionados, os quais são integrados pelo sentido de finalidade, de intencionalidade (Simon, 1970).

Obtém-se a integração e consistência dos comportamentos por meio da hierarquização de fins: "cada parte de um conjunto de comportamentos alternativos é comparada com uma escala abrangente de valores: a escala dos fins últimos” (Simon, 1970, p. 65).

No comportamento real, entretanto, tal integração dificilmente se dá num grau elevado de consciência: “a disposição dos motivos conscientes, ao invés de constituir uma hierarquia uniforme, é, geralmente, desordenada ou, para sermos mais precisos, uma coleção heterogênea de elementos ligados entre si de maneira frágil e incompleta” (Simon, 1970, p. 65).

De maneira geral, a decisão é desencadeada por estímulos, e o comportamento decorre, em sua maior parte, do hábito, que proporciona certo automatismo de respostas a situações similares. O hábito desempenha, desta maneira, função 
imprescindível ao comportamento planejado, representando um ajustamento, uma adaptação previamente condicionada (Simon, 1970).

Ao canalizar a atenção em direções definidas, excluindo as demais, os estímulos determinam quais são as decisões mais prováveis e influem de maneira decisiva nas conclusões do administrador. Isto significa que, mesmo sem integrar os objetivos de maneira consciente, a decisão sempre resultará no estabelecimento de pesos e numa síntese em particular (Simon, 1970). Assim, desmistifica-se a crença corrente de que é possível a existência de decisões meramente técnicas ou tecnicamente neutras.

O comportamento real jamais alcança racionalidade objetiva, uma vez que, antecipadamente, só é possível ter um conhecimento fragmentário das conseqüências de cada opção; a imaginação deve atribuir valores às conseqüências da opção, em lugar da experiência, e apenas uma fração de todas as possíveis alternativas é, de fato, considerada (Simon, 1970).

Em virtude dos limites da racionalidade, decorrentes "da incapacidade da mente humana de aplicar a uma decisão todos os aspectos de valor, conhecimento e comportamento que poderiam ter importância” (Simon, 1970, p. 113), a decisão representa, apenas, "a melhor solução encontrada naquelas circunstâncias" (Simon, 1970, p. 6). Já que o indivíduo não pode conhecer totalmente as conseqüências de suas ações, ele forma expectativas acerca das conseqüências futuras, com base na sua experiência prévia e nas informações que obtém sobre a situação.

Exercer a capacidade de observar, de projetar o passado e de utilizar fontes de referência, reduz a necessidade de experimentação real e permite que uma experiência relativamente pequena sirva de base para uma ampla variedade de decisões, promovendo economia considerável de esforço mental e de observação. Ao fazer uso do método experimental, da previsão teórica das conseqüências e da transmissão de conhecimentos, o homem demonstra toda a sua capacidade de aprender (Simon, 1970).

O estudo de Simon (1970) sobre o processo de decisão terminou produzindo contribuições seminais para se entender o processo de aprendizagem individual/ organizacional. Simon (1970) descreve o processo de decisão como sendo de aprendizagem, envolvendo uma fase de exploração e pesquisa, seguida de uma fase de adaptação. Destaca a importância das experiências prévias, da capacidade de abstração, a faculdade de comunicação e a memória, enquanto elementos distintivos da aptidão dos indivíduos para aprender. 


\section{A Atualidade das Proposições de Simon}

A obra de Simon (1970) reconcilia a teoria administrativa com a história e tem importância capital para os trabalhos subseqüentes dos teóricos evolucionários, particularmente preocupados com as maneiras como se introduz inovação, tecnologia e progresso técnico na economia capitalista, caso de Dosi, Teece e Winter (1992), Malerba e Orsenigo (1993), entre outros. O estudo das formas como se processa a seleção de paradigmas tecnológicos, a definição de estratégias e o acúmulo de competência nas firmas, será doravante influenciado pelas suas afirmações quanto à influência das decisões tomadas no passado e sobre a natureza restrita da racionalidade dos tomadores de decisão.

No campo dos estudos sobre estratégias, seu pressuposto de racionalidade restrita será incorporado literalmente por uns autores ou ampliado por outros, para dar conta das restrições à racionalidade emanadas dos interesses dos agentes estratégicos. Tendo como pontos em comum a visão de estratégias mais como processo do que como produto e a estreita vinculação entre estratégia e aprendizagem, no primeiro conjunto citado destacam-se Mintzberg e Waters (1985), com a tipologia de estratégia emergente e a percepção de que as estratégias realizadas situam-se em um continuum, cujos extremos são as estratégias deliberadas puras e as emergentes puras. No segundo conjunto, enquadram-se os autores filiados à Lógica de Ação, vertente francesa da sociologia das organizações (Amblard et al., 1996).

A sua afirmação acerca do papel primordial das instituições e, portanto, da organização, na constituição do framework a partir do qual a aprendizagem e a racionalidade se desenvolvem, encontra-se de acordo com alguns dos novos postulados do campo de conhecimento de ensino/aprendizagem, os quais tendem a delimitar o que neste trabalho convencionou-se chamar de vertente cognitivoconstrutivista. Entre tais postulados, destacam-se os que seguem.

- A mente passa a ser tratada como atividade, processo e produto de um organismo em interação, deixando de ser uma entidade independente do corpo, fonte da razão, do conhecimento e da verdade (Bastos, 2000a).

- A criação do conhecimento é, na verdade, fruto do mapeamento das ações e operações conceituais, que provaram ser viáveis na experiência do sujeito conhecedor. É, portanto, uma versão da realidade de natureza parcial, aproximativa e adaptativa, que deve ser levada em conta quando se pretende estimular/ melhorar a aprendizagem (Von Glasersfeld, 1998). Na organização, isso significa que ela sofre restrições advindas do corpo de conhecimento e do tipo de informações disponíveis, aceitos ou tidos como verdadeiros, e compartilhados pelos demais membros (Cabral, 2000). 
- A cognição é fenômeno intra e interpsíquico, porque tanto as estruturas cognitivas de indivíduos quanto os contextos sociais são relevantes no processo de cognição. Isto é, cognição e ação estão imbricadas, uma vez que o significado do comportamento/ação só se manifesta no curso da interação (Bastos, 2000a, 2000b).

- A aprendizagem depende não só da linguagem, mas também da interface entre conteúdo veiculado e experiências e conhecimentos prévios daquele que aprende (Miranda, 1999).

- Há climas favoráveis e desfavoráveis à aprendizagem. O clima deriva, por sua vez, da ambiência físico-estrutural, a exemplo da estrutura da organização, mas também de aspectos comportamentais, a exemplo dos que se estabelecem entre aprendiz e professor, entre lideranças e subordinados, e entre aprendizes (Miranda, 1999).

- As organizações possuem um framework que orienta o modo de perceber e orientar o mundo dentro do qual seus membros aprendem (Simon, 1970; Cabral, 2000).

- A aprendizagem organizacional depende da aprendizagem do indivíduo, que se transforma na primeira citada ao ser incorporada seletivamente à memória organizacional na forma de rotinas. Nas palavras de Simon (1970, p. 105): “o hábito, assim como a memória, possui um equivalente artificial na organização, e que foi denominado de rotina organizativa por Stene”.

Este último ponto dirige a atenção para a importância do mapeamento dos fatores que influenciam a aprendizagem dos indivíduos nas organizações, o que é objeto da pesquisa de campo realizada e cujos resultados serão relatados nos próximos itens deste trabalho. Antes de apresentá-los, porém, registram-se, a seguir, os procedimentos metodológicos adotados.

\section{Metodologia de Pesquisa}

A pesquisa desenvolvida buscou encontrar respostas dos entrevistados para a seguinte questão: que fatores condicionaram o processo de aprendizagem dos membros da Comissão de Seleção de Ferramenta CASE para as instituições de governo do Estado da Bahia, instituída pela PRODEB, em 2000?

Essa comissão foi formada por dez membros, sendo quatro representantes da 
PRODEB e um de cada uma das seguintes secretarias: Secretarias de Planejamento, Fazenda, Educação, Segurança, Administração e Saúde do Estado.

Foram pesquisados nove membros dessa comissão. Do total de entrevistados, três são da PRODEB e seis são representantes das secretarias já citadas.

As entrevistas seguiram roteiro semi-estruturado, contendo setenta e duas questões abertas, agrupadas em quatro dimensões da problemática: contexto, grupo, indivíduo, além de avaliação do processo de aprendizagem individual e dos resultados alcançados.

As respostas dos entrevistados foram classificadas em determinadas categorias operacionais de análise, as quais foram totalmente delimitadas após a avaliação de cada resposta dos nove entrevistados. As principais categorias analíticas são apresentadas no quadro a seguir.

\begin{tabular}{|c|c|}
\hline Categoria de análise & Definição \\
\hline Contexto institucional & $\begin{array}{l}\text { Elementos que compõem o ambiente mais geral no qual a organização está } \\
\text { inserida. }\end{array}$ \\
\hline Contexto operacional & $\begin{array}{l}\text { Elementos que derivam da natureza do negócio da organização, incluindo } \\
\text { clientes, fornecedores, tecnologias específicas, entre outros. }\end{array}$ \\
\hline Habilidades cognitivas & $\begin{array}{l}\text { Saber categorizar problemas técnicos e ver relações entre categorias; } \\
\text { compreender o particular por meio do conhecimento do geral (Motta, 1995). }\end{array}$ \\
\hline Habilidades interpessoais & $\begin{array}{l}\text { Capacidade de agregar e trabalhar com pessoas em função de objetivos comuns } \\
\text { (Motta, 1995). }\end{array}$ \\
\hline Habilidades analíticas & $\begin{array}{l}\text { Capacidade de decompor problemas, identificar variáveis fundamentais, } \\
\text { estabelecer relações de causa e efeito na busca de novas soluções, objetivos, } \\
\text { prioridades e alternativas de ação. }\end{array}$ \\
\hline Habilidades de comunicação & $\begin{array}{l}\text { Capacidade de comunicar aos membros do grupo os velhos e novos sentidos } \\
\text { aprendidos. }\end{array}$ \\
\hline Grupo de referência & $\begin{array}{l}\text { Comunidade técnica e profissional, à qual relaciona-se um conjunto específico } \\
\text { de interesses, valores e objetivos comuns. }\end{array}$ \\
\hline $\begin{array}{l}\text { Fatores internos e externos ao } \\
\text { grupo }\end{array}$ & $\begin{array}{l}\text { Enquanto os primeiros relacionam-se àqueles que só existem neste grupo } \\
\text { específico, isto é, se mudam as pessoas, podem deixar de ser válidos, os fatores } \\
\text { externos independem da constituição específica do grupo. }\end{array}$ \\
\hline Fatores psicossociais & Fatores psicológicos e culturais. \\
\hline Fatores comportamentais & $\begin{array}{l}\text { Fatores que especificam a forma como se dá a relação entre os indivíduos no } \\
\text { grupo, e dos indivíduos em relação à aprendizagem. }\end{array}$ \\
\hline Fatores de competência & $\begin{array}{l}\text { Conhecimentos técnicos na área de informática, conhecimento do negócio } \\
\text { governo e de suas organizações e do ambiente operacional de informática no } \\
\text { Estado da Bahia. }\end{array}$ \\
\hline Fatores de infra-estrutura & $\begin{array}{l}\text { Respostas sobre local físico de realização dos encontros da comissão, } \\
\text { equipamentos necessários à realização do trabalho e meios de comunicação, a } \\
\text { exemplo de Internet. }\end{array}$ \\
\hline
\end{tabular}

Por fim, considerando-se que um dos pesquisadores foi membro da referida comissão de seleção, as entrevistas, assim como a sistematização e categorização 
das respostas obtidas, foram realizadas por outro membro da equipe de pesquisadores, para minimizar vieses.

\section{Antecedentes: o Processo de Seleção de Ferramenta CASe para o Estado da Bahia, Brasil}

Com o objetivo de identificar uma ferramenta capaz de prover suporte ao desenvolvimento e manutenção de sistemas nas várias unidades que compõem o Estado da Bahia e, sobretudo, de organizar e difundir os dados coletados e produzidos no âmbito do Estado, a PRODEB instituiu, em 11/5/2000, uma Comissão de Seleção de Ferramenta CASE $^{(1)}$.

Buscando tornar o processo de seleção transparente, imparcial, objetivo e capaz de ser repetido, decidiu-se tomar, como referência para seu desenvolvimento, a Norma de Orientação para Avaliação e Seleção de Ferramenta CASE, da Associação Brasileira de Normas Técnicas - ABNT (NBR ISO/IEC 14102/ 1999), a qual define um método e oferece grande elenco de características a serem avaliadas.

A seleção foi precedida de fase preparatória (janeiro de 2000 à abril de 2000), sob a responsabilidade de técnicos da PRODEB. Essa fase envolveu atividades consistentes com os processos de Iniciação e Estruturação prescritos pela norma. Durante a etapa de Iniciação, estabeleceram-se a direção e o gerenciamento do processo; na de Estruturação, organizaram-se os requisitos e obtiveram-se informações sobre as ferramentas disponíveis no mercado.

A partir de maio de 2000, ocorreram as fases de Avaliação e Seleção. Inicialmente, a norma foi apresentada à comissão de seleção, juntamente com a sugestão de características a serem avaliadas, tipificadas em desejáveis e obrigatórias, desenvolvida pela equipe da PRODEB. Essas características foram agrupadas em quatro grandes conjuntos: (1) aquelas referentes aos processos do ciclo de vida do software propriamente dito, abrangendo modelagem, construção, manutenção, documentação etc.; (2) as relativas ao uso da ferramenta, envolvendo o ambiente e a forma de funcionamento da ferramenta; (3) características relativas à qualidade do produto: facilidade de uso, funcionalidades disponíveis, entre outras; e (4) as características do fornecedor e do produto, tais como tipo de suporte oferecido, localização do fornecedor, planos para evolução do produto, tempo no mercado. Em seguida, a comissão atribuiu a cada um dos grandes grupos de características, um peso de acordo com seu nível de importância: 1 Baixo; 2 - Regular; 3 - Bom; 4 - Alto. 
O quadro a seguir apresenta os níveis de importância atribuídos aos grandes grupos de características avaliadas.

\begin{tabular}{|c|c|c|}
\hline Item da Norma & Conjunto de Características & Nível de Importância \\
\hline 9.1 & Processo de Ciclo de Vida & 4 \\
\hline 9.2 & Uso da Ferramenta CASE & 4 \\
\hline 9.3 & Qualidade & 3 \\
\hline 9.4 & Fornecedor e Produto & 3 \\
\hline
\end{tabular}

O Plano de Avaliação elaborado pela comissão previu: (1) a coleta de informações junto a três fornecedores, por meio de questionário, para se verificar a capacidade de as ferramentas candidatas atenderem a todas as características (desejáveis e obrigatórias); e (2) a demonstração da facilidade de implementar as características mais importantes para a consecução dos objetivos.

Para cada característica atendida, computou-se valor 1. Em alguns casos, pontuouse, em ordem crescente, de 1 a 3, segundo a maior ou menor adequação de cada ferramenta à característica avaliada. O somatório dos pontos obtidos para cada conjunto de características foi multiplicado pelo nível de importância a ele atribuído.

A apresentação dos fornecedores foi orientada por um modelo simplificado, elaborado pela comissão, simulando algumas situações críticas para o gerenciamento e garantia da qualidade do acervo de dados do Estado. A comissão de seleção reuniu-se, posteriormente, para nivelar o entendimento das facilidades apresentadas. Na ocasião, os técnicos especialistas em rede convidados pela comissão para assistirem as apresentações, com base em suas avaliações sobre o desempenho durante a simulação, deram seus pareceres sobre o grau de adequação entre ferramentas demonstradas e ambiente físico de operação.

Cada avaliador atribuiu valor de 1 a 4 (1 - Ruim; 2 - Regular; 3 - Bom; 4 Muito Bom) a cada uma das características apresentadas pelos fornecedores. Obteve-se a média aritmética dos pontos obtidos para cada ferramenta, multiplicada, em seguida, pelo nível de importância atribuído.

Para efeito de pontuação final, atribuiu-se peso 3 para os pontos obtidos por cada ferramenta, a partir do questionário respondido pelos fornecedores, e peso 7 para os pontos obtidos por elas na apresentação. Essa distribuição de pesos reflete a constatação de que o grande diferencial entre as ferramentas encontrase no modo como cada uma implementa as características avaliadas: a forma como o fazem torna seus processos mais ou menos amigáveis ao usuário e seus produtos mais ou menos confiáveis. 
As pontuações individuais foram analisadas criticamente pela comissão, tendo em vista os objetivos perseguidos. Essa reflexão, recomendada pela norma, justifica-se como recurso para corrigir vieses tecnicistas na atribuição dos pesos, que possam distorcer as escolhas.

\section{O que os Participantes da Comissão Consideram que Aprenderam}

O resultado da pesquisa realizada com nove membros da Comissão de Seleção de Ferramenta CASE indica que todos eles consideram que aprenderam algo novo. Isto é, que durante a experiência de trabalho na comissão reelaboraram e agregaram novos conhecimentos à base preexistente. Os novos conhecimentos, ainda segundo os mesmos entrevistados, foram fundamentalmente de natureza técnica - conceitos avançados da área de informática. Entretanto, apesar da maior concentração de respostas ligadas a conhecimentos técnicos da área de informática, foi indicado aprendizado sobre metodologia e sobre organização de processo de seleção. Houve referências, ainda, ao aprendizado sobre o contexto da área de informática no Estado e ao desenvolvimento de habilidades interpessoais. De acordo com um dos técnicos entrevistados, "ele aprendeu a lidar com pessoas".

Todos consideram que a aprendizado foi significativo, porque terá repercussões sobre suas vidas profissionais. Foi significativa também a experiência, a qual todas esperam ver replicada, embora não haja unanimidade na avaliação dos resultados alcançados: quatro entrevistados classificaram os resultados como muito bom, quatro como bom e um como ruim. Apenas um dos entrevistados admitiu que o processo de seleção de ferramentas por comissão não deve ser repetido pelo Estado.

Em vista disso, a pesquisa realizada junto à comissão buscou identificar os fatores do contexto, do grupo e do indivíduo que, de acordo com a ótica dos entrevistados, teriam influenciado o seu processo de aprendizagem. Os resultados coletados nas entrevistas são relatados a seguir. 


\section{Fatores Condicionantes do Processo de Aprendizagem, Segundo a Visão dos Entrevistados}

\section{Contexto}

Os resultados da pesquisa revelam que o contexto para os entrevistados tem várias dimensões: o contexto institucional, cujos limites são comparativamente mais amplos, e o contexto operacional, cujos elementos são mais ligados ao negócio de informática, da empresa e das secretarias, conforme explicitado em item anterior. Alguns dos fatores do contexto institucional que favoreceram o trabalho e o aprendizado ressaltados pelos entrevistados foram: "interesse comum entre as secretarias"; "pressão dos organismos internacionais por um sistema de informação que viabilize a avaliação dos projetos por eles financiados"; e "decisão do Estado de modernizar-se”. No segundo grupo de fatores favoráveis, foram enquadradas, entre outras, respostas do tipo: "diagnóstico preexistente sobre sistema de informação do Estado"; "existência de cliente interessado em ferramenta CASE”; "interesse da PRODEB em trabalhar junto com clientes”.

Já em relação aos fatores do contexto que restringiram o trabalho do grupo e, conseqüentemente, o processo de aprendizagem, os mesmos entrevistados indicaram, principalmente, os derivados da falta de comprometimento dos escalões superiores com o trabalho de comissão (9 citações); a complexidade do trabalho de avaliação e do ambiente de informática do Estado (2 citações); e resistência a mudanças (2 citações).

\section{Grupo}

No conjunto de respostas dos entrevistados, as habilidades cognitivas e de competência (conhecimento técnico sobre informática e sobre o ambiente de informática do Estado, principalmente) foram as mais referidas (15 citações) como características do grupo que favoreceram o trabalho e a aprendizagem. Fatores culturais também foram indicados como muito importantes, a exemplo de "interesse profissional de todos no assunto" (2 citações); "todos trabalham no Estado” (1 citação); “competência básica comum a todos” (3 citações). É importante enfatizar que todas as indicações estão relacionadas à cultura técnica comum ao grupo e que, por isso, podem ser classificadas também como fatores relacionados a grupo de referência. Por último, compareceram os fatores psicológicos, entre os quais destacam-se: "determinação de fazer o trabalho"; "vontade de aprender sobre uma área cujo conhecimento não era totalmente dominado"; e "interesse pessoal". 
Entre as habilidades agrupadas como cognitivas e entre os fatores de competência, em especial, chamam a atenção os seguintes aspectos: a valorização da diversificação de conhecimentos específicos na área de informática, o que indica o reconhecimento da complementaridade de competência entre os membros do grupo, apesar da origem profissional comum - apenas um deles não é formado em processamento de dados; a diversificação de experiências acumuladas, embora sejam todos funcionários do Estado ou trabalhando para o Estado; e a visão abrangente não só sobre suas secretarias de origem, mas também sobre o contexto da tecnologia de informação no Estado.

Em relação às características do grupo restritivas ao trabalho e ao processo de aprendizagem, os fatores relacionados a habilidades cognitivas de seus membros foram novamente os mais citados. É importante ressaltar ainda que, entre os fatores referidos por último, a heterogeneidade de conhecimentos entre os membros do grupo foi apontada como um elemento que, paradoxalmente, teria concorrido para restringir a aprendizagem, uma vez que relacionado a esta teria ocorrido baixa comunicabilidade entre os membros que usavam uma linguagem técnica muito heterogênea. Tal fato parece sugerir que há um ótimo de diversificação de conhecimentos para potencializar processos de aprendizagem em áreas especializadas.

As armadilhas de competência ficaram explícitas, uma vez que os entrevistados declararam que "as experiências e os conhecimentos técnicos prévios [às vezes] funcionaram como obstáculos à comunicação e ao aprendizado". Esse pré-conhecimento foi citado ainda como a base para comportamentos "resistentes a mudar pontos de vista/preferências”.

Perguntados sobre os cinco principais recursos estratégicos para o trabalho que teriam sido disponibilizados, os entrevistados elencaram, em primeiro lugar, a metodologia (55 citações). Em segundo lugar, indicaram recursos de infra-estrutura (32 citações), enquanto em terceiro lugar citaram recursos humanos (28 citações).

Simultaneamente, recursos de natureza metodológica, como "conjunto mais amplo de fornecedores envolvidos com o processo", "tempo de apresentação para cada fornecedor" e "conjunto mais diversificado de secretarias envolvidas no trabalho", ocuparam o primeiro lugar do ranking de recursos estratégicos para o trabalho do grupo que não foram disponibilizados.

Longe de representar contradição ou inconsistência das repostas dos entrevistados, a classificação da metodologia como o recurso estratégico mais importante disponibilizado e não disponibilizado para a consecução dos objetivos do grupo, parece demonstrar o alto grau de importância atribuído pelos indivíduos a recursos dessa natureza em processos de aprendizagem em grupo, assim como a variedade de elementos que podem ser classificados nessa categoria. 
A importância do learning by interacting foi confirmada pelos entrevistados, que consideraram, em regra, terem aprendido com as apresentações e informações fornecidas por meio de questionário pelos fornecedores, embora todos tenham feito críticas, sobretudo, às apresentações. Segundo a maioria dos entrevistados nem todos os fornecedores se prepararam para as apresentações e alguns deles foram mal representados. De acordo com a ótica da maioria dos entrevistados, os fornecedores, ou seus representantes locais, não se preocuparam com a audiência ou minimizaram a sua competência.

A literatura sobre aprendizagem organizacional tem apontado a existência de climas favoráveis ou desfavoráveis ao aprendizado. Esta pesquisa procurou identificar como os entrevistados avaliaram o clima no grupo.

A maioria dos entrevistados considerou que o clima no grupo foi favorável ao aprendizado porque as pessoas sentiam-se à vontade para externar pontos de vista próprios, uma vez que "os participantes tinham características e status semelhantes", conforme afirmou um dos entrevistados. Houve um entrevistado cuja opinião destacou-se da maioria. Segundo ele, houve elementos favoráveis e não favoráveis em termos de clima no grupo. A falta de nivelamento de conhecimentos entre os membros e a resistência em mudar pontos de vistas, foram aspectos que contribuíram para a existência de clima no grupo não favorável ao aprendizado. Apesar de a maioria opinar sobre a existência de clima favorável, o nível de participação dos membros foi considerado bom por apenas cinco entrevistados, enquanto outros três avaliaram-no como médio e um considerou que o clima melhorou ao longo do processo.

Com base nas respostas dos entrevistados, foi possível fazer o Ranking dos Principais Fatores de Clima Favoráveis à Externalização de Pontos de Vista. A primeira listagem obtida foi reagrupada entre fatores internos e externos ao grupo. Do total obtido, 80 citações referiam-se a fatores internos ao grupo, enquanto 27 citações relacionavam-se a fatores externos. Entre os fatores classificados como internos ao grupo, destacam-se: 41 citações de grupos de referência ("as pessoas se conheciam previamente"; "todos os participantes eram técnicos”; “características e status semelhantes”); 30 citações de aspectos comportamentais ("postura independente"; "todos deram oportunidade ao outro de falar”); 9 citações de aspectos relacionados a competência técnica ("as pessoas dominavam o assunto"; "todos os participantes tinham muita experiência”). Chamou a atenção, ainda, um conjunto de respostas que realçava a existência de interesses comuns entre os membros do grupo como fator que teria favorecido a externalização dos pontos de vista dos participantes e que foi, de acordo com a metodologia, incluído em "grupos de referência”. 
O mapeamento das capacitações necessárias para desempenhar o papel na Comissão de Seleção de Ferramenta CASE também foi realizado. De acordo com os entrevistados, o grupo deveria reunir conhecimentos técnicos na área de informática, especialmente sobre desenvolvimento de sistemas, administração de dados, banco de dados, documentação de sistemas, ferramentas CASE e suas áreas de aplicação, entre outros. No entanto essas capacitações específicas deveriam ser complementadas com outros conhecimentos, a exemplo de conhecimentos sobre organização de processos de seleção, metodologia de análise, Lei Estadual de Licitação e visão do negócio governo. Todos declararam possuir as capacitações anteriormente mencionadas, à exceção de um deles. Esse entrevistado admitiu que o grupo reunia "pouco conhecimento sobre os produtos que iriam ser obtidos com as ferramentas e pouco conhecimento geral”. Os pesquisados consideraram também importante para potencializar os resultados e o processo de aprendizagem, o fato dos objetivos estarem claramente definidos.

O mapeamento das características das reuniões do trabalho foi realizado no sentido de tentar estabelecer relações dessas características com a aprendizagem do grupo. Essa parte da pesquisa trouxe à tona alguns dados contraditórios tanto com relação à definição prévia de pautas, quanto com relação à periodicidade das reuniões. Uma explicação para esta aparente contradição ou inconsistência das respostas é que houve muita intermitência na presença dos membros às reuniões.

Do ponto de vista dos conteúdos, as reuniões foram classificadas pelo grupo como "muito ricas", com "pautas previamente definidas e conhecidas pelos participantes, que podiam sugerir mudanças" (8 citações). Do ponto de vista do processo, ressaltaram "as discussões acirradas, freqüentes e focadas” (3 citações), mas que levaram ao consenso, segundo um dos entrevistados. Para outro entrevistado, "muito tempo das reuniões foi consumido em discussões em função da falta de nivelamento de conceitos entre os participantes”. Em função disso, talvez se explique a referência feita por outro entrevistado de que "a discussão focalizada de cada item do questionário tenha ficado prejudicada".

A maioria dos entrevistados (7 em um total de 9 pessoas) considerou que o grupo selecionou a melhor ferramenta. Isso porque é uma ferramenta que "permite a administração dos dados do Estado de maneira confiável e segura"; "é a ferramenta mais completa, possui banco próprio para ser repositório"; "foi a que mostrou melhor desempenho na demonstração"; "foi a que mostrou flexibilidade na aplicação do modelo”. A análise dessas respostas permite concluir que os critérios de avaliação da ferramenta, enfatizam a sua adequação aos objetivos fixados para o trabalho do grupo (8 citações), enquanto apenas duas enfatizam o princípio de eficiência como parâmetro para avaliar a ferramenta escolhida. 


\section{Indivíduo}

A maioria dos entrevistados (cinco pessoas) considerou que o seu conhecimento prévio era suficiente para desempenhar o papel na comissão de seleção, enquanto quatro o avaliaram como insuficiente.

Do conjunto de 13 habilidades pessoais estratégicas mencionadas pelos entrevistados, 14 citações referem-se a habilidades cognitivas, a exemplo de, entre outras, "conhecimento de pelo menos uma das ferramentas em análise" (4 citações), "domínio de conceitos envolvidos nas três ferramentas" (4 citações), "conhecimento sobre o ambiente operacional da PRODEB" (2 citações) e "conhecimento do negócio governo" (1 citação). A única habilidade pessoal comportamental, que define a maior/menor possibilidade de relacionar-se com o outro, citada apenas uma vez, foi "saber ouvir e ter disposição para ajudar". Habilidades analíticas e de comunicação escrita foram mencionadas ainda como integrantes do rol de competências individuais de apenas um membro do grupo.

Do conjunto de habilidades cognitivas individuais, a maioria dos entrevistados (6 pessoas) declarou que os conhecimentos específicos de informática foram os mais utilizados ao longo do processo de seleção da ferramenta CASE. É interessante observar, também, que as maiores lacunas de competência citadas pelos mesmos entrevistados são de habilidades cognitivas específicas, como sobre "as ferramentas em análise” (3 citações), “conceitos avançados nas áreas de desenvolvimento de sistemas e de banco de dados" (1 citação) e "técnicas de construção de modelos” (1 citação), o que reforça a indicação anterior sobre um ótimo de complementaridade entre conhecimentos em processos de aprendizagem especializada.

Segundo o depoimento dos entrevistados, vários caminhos foram ativados por eles para suprir as lacunas de competência, sendo os principais: "discussões com o grupo" (6 citações), "pesquisa na Internet” (3 citações) e “discussão com os fornecedores” (2 citações).

É interessante observar que o foco nos fatores que podem favorecer ou dificultar a aprendizagem, vai se ajustando e apresentando menor número de variação em termos de categorias, quando os entrevistados são estimulados a responder sobre sua experiência em particular. Tal tendência já é nítida desde a identificação dos fatores do contexto. A análise das respostas dos entrevistados sobre os fatores do contexto que teriam favorecido sua aprendizagem individual, indicou que todos os elementos considerados são pertencentes, exclusivamente, ao contexto operacional. São eles: aspectos vinculados à metodologia (4 citações), a exemplo de "participação de diferentes secretarias”, "participação dos fornece- 
dores”, "participação de técnico da CELEPAR”, entre outros; aspectos vinculados a grupo de referência (5 citações), como "experiências prévias em outras secretarias", "trajetórias anteriores dentro das organizações"; aspectos estruturais e comportamentais de atores do ambiente operacional, cujos exemplos são "o COMIN - Conselho de Modernização e Informática ter estado até recentemente dentro de certa secretaria” e "determinação da gerência da PRODEB de realizar o processo".

As respostas sobre os fatores do grupo que teriam favorecido a aprendizagem individual, vinculam-se estritamente a comportamentos dos membros ou a comportamentos que pressupõem competências: nessas duas categorias foram agrupadas 12 citações em um conjunto de 13. Citações ilustrativas da primeira categoria são: “clima de abertura de discussão” (5 citações), “disposição para socializar conhecimentos” (1 citação), “disposição para ensinar” (1 citação); na segunda categoria, "ter acesso ao conhecimento do outro" (4 citações), "existência de interlocutores" (1 citação). A única resposta enquadrada na categoria competência foi "conhecimento diversificado entre os membros do grupo" (1 citação). Esse ajustamento de foco também foi observado em relação aos fatores do grupo que teriam sido desfavoráveis à aprendizagem individual. Em relação a esses últimos fatores, chamou a atenção ainda o fato de que 5 dos 9 entrevistados tenham declarado que tais fatores não existiram.

Os aspectos psicológicos são quase os únicos nas respostas dos entrevistados sobre os fatores pessoais que teriam favorecido o seu aprendizado. Foram citados e classificados na categoria de aspectos psicossociais: "ser extrovertido ", "ser objetivo “, "ter disposição para escutar”, "ter paciência”, "ser dedicado”, "não ter medo de correr risco de errar", "ser otimista”, "ser aberta para o novo". Apenas um entrevistado citou uma habilidade de competência: "facilidade de interpretação de texto". No campo dos fatores pessoais que teriam restringido o aprendizado individual, podem-se observar respostas classificáveis na categoria de fatores psicossociais; entretanto tais fatores seriam fruto da relação com o outro, ou seja, de relações interpessoais, tais como "desgaste após discussão", "insegurança após discussão", "medo de ser vista como complicadora de processos". Nesse aspecto houve ainda citações classificadas como exclusivamente psicológicas, cujas ilustrações são: “pouca paciência”, "ser centralizadora”, “ser mais observador". 


\section{Conclusões e Recomendações}

Olhando-se tais resultados à luz da discussão teórica delineada anteriormente, quais são as principais ilações?

Parece que os resultados obtidos são consistentes com alguns dos postulados do que se convencionou chamar, neste trabalho, de vertente cognitivo-construtivista da aprendizagem. Tais postulados são os que seguem.

- A relação entre aprendizagem (criação de conhecimento), ações e operações conceituais classificadas como viáveis pelo sujeito conhecedor e pelas organizações, que refletem uma versão da realidade de natureza parcial, porque orientadas por frameworks. Isso foi demonstrado pelas citações recorrentes dos entrevistados a suas competências específicas como fator facilitador do seu próprio aprendizado e do grupo; pelas citações dos fatores de grupo de referência também como elementos facilitadores do mesmo processo e pelas referências à diversificação/ complementaridade entre os conhecimentos dos membros do grupo, tanto como fator de facilitação, tanto como fator de restrição dos processos de aprendizagem grupal e individual. Além dessas citações, corroboram tal postulado a explicitação do fato dos objetivos estarem claramente definidos e a qualificação da ferramenta escolhida como a melhor porque era a que mais se adequava aos objetivos colocados para o grupo.

- A cognição vista como processo intra e interpsíquico. Isso foi evidenciado pelas respostas dos entrevistados, que realçavam tanto aspectos de comportamento dos indivíduos no grupo como aspectos seus particulares, especialmente suas características psicológicas, como fatores que teriam favorecido a sua aprendizagem pessoal.

- A aprendizagem depende da comunicação de conteúdos, o que põe em relevo a questão da linguagem e dos conhecimentos prévios. Foi mencionada pelos entrevistados a ocorrência de ruídos de comunicação, em função de os elementos do grupo não terem uma compreensão uniforme sobre determinados termos técnicos, que se perdeu muito tempo em discussões porque havia diversidade de interpretação dos termos técnicos. Novamente, aqui, cumpre mencionar a recorrente indicação da diversificação de conhecimentos do grupo e sua competência específica na área de informática como elementos facilitadores e, simultaneamente, redutores do processo de aprendizagem. 
- A importância do clima para a aprendizagem e o papel dos fatores de infra-estrutura e das relações interpessoais na criação de clima favorável/desfavorável. Os fatores de infra-estrutura foram enfatizados nas respostas dos entrevistados vinculadas à dimensão contexto. Os fatores de clima também foram referidos nas respostas dentro da última dimensão citada, mas foram ganhando proeminência progressiva, à medida que se avançou para as outras duas dimensões na entrevista - grupo e indivíduo.

\section{- A autonomia apenas relativa entre aprendizagem individual e aprendi-} zagem organizacional. Isso porque, segundo os entrevistados, ocorreu aprendizado. Mas não se pode dizer que este já é um aprendizado organizacional, embora a PRODEB esteja, atualmente, replicando a experiência, uma vez que ainda não se transformou em rotina organizacional e ainda é uma experiência muito recente.

\section{- O processo de interação social como lugar de negociação de sentidos,} constituindo-se, portanto, em contexto no qual se verifica a sua adaptação.

- A ênfase sobre os modos como se realiza a relação aprendiz-contexto e o destaque sobre o potencial comunicativo dos conteúdos que, à luz do construtivismo, adquire a feição particular de jogo dialético entre processos de assimilação/acomodação.

Como foi registrado na Introdução, a intenção deste artigo é a de relatar resultados de uma pesquisa, cujo objetivo principal foi mapear fatores determinantes da aprendizagem do indivíduo nas organizações. Esses resultados evidenciaram algumas postulações do campo cognitivo-construtivista, conforme já comentado. Cumpre agora apontar que a opção por técnicas qualitativas de pesquisa, ensejou a captação das diferentes visões dos entrevistados, mas, ao mesmo tempo, aumentou o risco de viés na interpretação dos resultados, porque "descrever a realidade não é somente representá-la, como se fosse um espelho que apenas reflete a imagem, mas reconstruí-la” (Demo, 2000, p. 52). Enfim, admite-se que, aqui também, os frameworks das autoras podem ter orientado suas ações, construções conceituais e interpretação dos dados da pesquisa.

\section{Nota}

${ }^{1}$ Ferramentas CASE (Computer Aided System Engineering) automatizam os processos de engenharia de software, provendo suporte básico na sua concepção, construção, manutenção e documentação. 
ReferênCias Bibliográficas

AMBLARD, H. et al.

Les nouvelles approches sociologiques des organisations. Paris: Seuil, 1996.

BASTOS, A. V. B.

Organizações como 'corpus de pensamento e ação': o olhar cognitivista e suas implicações para a gestão de pessoas. [S.I.], 2000a. mimeo.

Organização e cognição: o que emerge desta interface? [S.l.], 2000b. mimeo.

BRITO, M. J. de; BRITO, V. da G. P.

Aprendizagem nas organizações: paradigmas de análise, teoria e cultura organizacional. Organizações \& Sociedade, v. 4, n. 10, p. 15-41, set./dez. 1997.

\section{CABRAL, A. C. de A.}

Aprendizagem organizacional como estratégia competitiva. In: RODRIGUES, S. B.; CUNHA, M. P. (Orgs.). Estudos organizacionais: novas perspectivas na administração de empresas - uma coletânea luso-brasileira. São Paulo: Iglu, 2000.

COOK, S. D. N.;

YANOW, D.

Culture and organizational learning. In: COHEN, M. D.; SPROULL,

\section{S. (Eds.). Organizational} learning - organization science. London: Sage Publications, 1996. p. 430-459.

DEMO, P.

Metodologia do conhecimento científico. São Paulo: Atlas, 2000.

DOSI, G.;

TEECE, D. J.;

WINTER, S.

Toward a theory of corporate coherence: preliminary remarks. In: DOSI, G.; GIANNETTI, R.; TONINELLI, P. A. (Eds.). Technology and enterprise in a historical perspective. Oxford: Clarendon Press, 1992. p. 185-209.

HUYSMAN, M.

Balancing biases: a critical review of the literature on organizational learning. In: EASTERBYSMITH, M.; BURGOYNE, J.; ARAUJO, L. Organizational learning and the learning organization. [S.l.: s.n]: [19__].

LEVITT, B.;

MARCH, J. G.

Organizational learning. In: COHEN, M. D.; SPROULL, L. S. (Eds.). Organizational learning - organization science. London: Sage Publications, 1996. p. 516-539. 
LÉVY, P.

As tecnologias da inteligência:

o futuro do pensamento na era da informática. Rio de Janeiro: Editora 34, 1993.

MALERBA, F.;

ORSENIGO, L.

Technological regimes and firm behavior. Industrial and Corporate Change, v. 2, n. 1, p. 45-71, 1993.

MINTZBERG, H.;

WATERS, J.

Of strategies, deliberate and emergent. In: DAVID, A.; BOWMAN, C. (Eds.). Readings in strategic management. London: MacMillan, 1985.

MIRANDA, T. G.

A linguagem e o pensamento na elaboração conceitual. Revista de Educação e Cultura, v. 1, n. 1, p. 147-166, 1999.

MOTTA, P. R.

Gestão contemporânea: a ciência e a arte de ser dirigente. 5 . ed. Rio de Janeiro: Record, 1995.

NELSON, R. R.

Understanding technical change as an evolutionary process. North-Holland: [s.n.], 1987.
PRODEB.

Seleção de ferramenta CASE para o Estado da Bahia. Relatório Final, Salvador, 2000.

SIMON, H. A.

Comportamento administrativo: estudo dos processos decisórios nas organizações administrativas. 2. ed. rev. Rio de Janeiro: FGV, 1970.

VON GLASERSFELD, E.

Construtivismo: aspectos introdutórios. In: FOSNOT, C. T. (Org.). Construtivismo: teoria, perspectivas e prática. Porto Alegre: ArtMed, 1998. p. 19-23.

WEICK, K. E.

The nontraditional quality of organizational learning. In: COHEN, M. D.; SPROULL, L. S. (Eds.). Organizational learning organization science. London: Sage Publications, 1996. p. 163-173.

WINTER, S. G.

Organizing for continuous improvement: evolutionary meets the quality revolution. COHEN, $\mathrm{M}$. D.; SPROULL, L. S. (Eds.). Organizational learning organization science. London: Sage Publications, 1996. p. 460-483. 